\title{
Excreción urinaria de sodio y potasio: asociación con la presión arterial, la mortalidad y los eventos cardiovasculares
}

Urinary sodium and potassium excretion: association with blood pressure, mortality and cardiovascular events

Mente A y col. N Engl J Med 2014;371:601-11

O'Donnell M y col N Engl J Med 2014;371:612-23

\section{Objetivos}

Establecer la asociación de la excreción urinaria de sodio y potasio con los valores de presión arterial, la mortalidad y los eventos cardiovasculares mayores (muerte por causa cardiovascular, infarto de miocardio, accidente cerebrovascular o falla cardiaca).

\section{Diseño y pacientes}

Cohortes prospectivas, cuyos participantes habían sido incluidos en el estudio PURE (Prospective Urban Rural Epidemiology study); 157.543 personas de 35 a 70 años, de 18 países de bajos, medianos y altos ingresos.

\section{Métodos y análisis estadístico}

Se estimó la excreción urinaria de 24 horas de sodio y potasio a partir de una sola muestra de orina a la mañana, mediante la fórmula de Kawasaki, y sus valores fueron utilizados como subro- gante de consumo de estos minerales. Se aplicó un modelo de regresión lineal multivariable, y se realizaron análisis adicionales para explorar el sesgo de dilución y de causalidad inversa.

\section{Resultados principales}

La excreción media de sodio fue de 4,93 $\pm 1,73 \mathrm{~g} /$ día y la de potasio, de $2,12 \pm 0,60 \mathrm{~g} / \mathrm{dí}$. Los principales resultados relacionados con la excreción de sodio se presentan en las tablas 1 y 2 . Por cada gramo de aumento en la excreción de potasio, disminuyó $1,08 \mathrm{mmHg}$ la presión arterial sistólica y $0,09 \mathrm{mmHg}$ la presión arterial diastólica. Todos los grupos de mayor excreción de potasio presentaron menor riesgo de mortalidad global y de eventos cardiovasculares mayores en comparación con el grupo de excreción menor de 1,5g/día; asociación que se mantuvo al realizar el análisis con la exclusión de los sujetos con enfermedad cardiovascular de base, cáncer o que sufrieron eventos durante el primer año.

Tabla 1. Cambios en la presión arterial sistólica y diastólica por cada gramo de aumento en la excreción de sodio.

\begin{tabular}{|c|c|c|}
\hline & Presión arterial sistólica (IC 95\%) & Presión arterial diastólica (IC 95\%) \\
\hline Global & $2,11(2,00$ a 2,22$)$ & $0,78(0,71$ a 0,85$)$ \\
\hline \multicolumn{3}{|c|}{ Excreción urinaria de sodio } \\
\hline$<3 \mathrm{~g} /$ día & $0,74(-0,36$ a 1,84$)$ & $-0,09(-0,76$ a 0,58$)$ \\
\hline 3 a 5 g/día & $1,74(1,29$ a 2,19$)$ & $0,92(0,65$ a 1,19$)$ \\
\hline$>5 \mathrm{~g} / \mathrm{di} a$ & $2,58(2,38$ a 2,78$)$ & $0,96(0,84$ a 1,97$)$ \\
\hline \multicolumn{3}{|c|}{ Hipertensión arterial } \\
\hline No & $1,30(1,23$ a 1,38$)$ & $0,58(0,52$ a 6,63$)$ \\
\hline Si & $2,49(2,34$ a 2,64$)$ & $0,91(0,82$ a 1,07$)$ \\
\hline \multicolumn{3}{|l|}{ Edad } \\
\hline$<45$ años & $1,96(1,81$ a 2,11$)$ & $0,97(1,07$ a 1,87$)$ \\
\hline 45 a 55 años & $2,43(2,25$ a 2,61$)$ & $1,08(0,97$ a 1,19$)$ \\
\hline$>55$ años & $2,97(2,78$ a 3,17$)$ & $1,21(1,10$ a 1,32$)$ \\
\hline
\end{tabular}

IC 95\%: Intervalo de confianza del 95\%.

Tabla 2. Asociación de la excreción urinaria estimada de sodio con la mortalidad global y los eventos cardiovasculares mayores (resultado primario combinado)

\begin{tabular}{|c|c|c|c|}
\hline & \multicolumn{3}{|c|}{ Excreción urinaria estimada de sodio Odds Ratio ajustado (IC 95\%) } \\
\hline & $<3 \mathrm{~g} / \mathrm{dia}$ & 4,00 a $5,99 \mathrm{~g} / \mathrm{di} i \mathrm{a}$ & $>7 \mathrm{~g} / \mathrm{dia}$ \\
\hline Anfisis primario & $1,27(1,12$ a 1,44$)$ & 1,00 & $1,15(1,02$ a 1,30$)$ \\
\hline Análisis excluyendo los sujetos con enfermedad cardiovascular de base & $1,24(1,07$ a 1,42$)$ & 1,00 & $1,14(1,01$ a 1,29$)$ \\
\hline Análisis excluyendo los individuos con antecedentes de cáncer & $1,26(1,11$ a 1,43$)$ & 1,00 & $1,15(1,02$ a 1,29$)$ \\
\hline Análisis excluyendo los eventos del primer año & $1,33(1,17$ a 1,52$)$ & 1,00 & $1,16(1,01$ a 1,33$)$ \\
\hline
\end{tabular}

\section{Conclusiones}

La ingesta de sodio de 3 a $6 \mathrm{~g} /$ día se asoció con un menor riesgo sumos diarios mayores o menores. La excreción de potasio mayor de mortalidad y de eventos cardiovasculares, respecto de con-

de 1,5g/día se asoció a un mayor riesgo de estos eventos.

\section{Comentario}

Las guías actuales recomiendan un consumo máximo de sodio de 1,5 a 2,3 g/día en base a estudios de cohorte prospectivos con resultados contradictorios entre la asociación del consumo de sodio y las tasas de eventos cardiovasculares y muertes ${ }^{1}$. Estos estudios sugieren que la excreción urinaria de sodio menor de $3 \mathrm{~g} /$ día se asocia con un mayor riesgo de mortalidad global y de sufrir eventos cardiovasculares mayores, aunque solo el $2 \%$ de la población general excreta esos niveles, dado que los alimentos contienen sodio y resulta difícil llegar a restringirlo completamente de la dieta. La principal limitación de los estudios comentados radica en que los niveles de consumo de sodio y de potasio se estimaron a través de la excreción urinaria de 24 horas, la que se obtuvo haciendo una extrapolación de la primera orina de la mañana.

\section{Conclusiones del comentador}

El consumo de sodio diario en cantidades extremadamente pequeñas parece asociarse tanto como su exceso con un aumento de la presión arterial, la mortalidad por todas las causas y el riesgo de eventos cardiovasculares.

Francisco Peper [ Servicio de Medicina Familiar y Comunitaria del Hospital Italiano de Buenos Aires. francisco.peper@ hospitalitaliano.org.ar ]

Peper F. Excreción urinaria de sodio y potasio: asociación con la presión arterial, la mortalidad y los eventos cardiovasculares. Evid Act Pract Ambul 2015;18(1)13 Ene'Mar. Comentado de: Mente A, y col. Association of Urinary Sodium and Potassium Excretion with Blood Pressure. N Engl J Med 2014;371:601-11. PMID: 25119606; y O'Donnell M, y col. Uninary Sodium and Potassium Excretion, Mortality, and Cardiovascular Events. N Engl J Med 2014;371:612-23. PMID: 25119607.

Referencias bibliográficas

1. Eckel RH, Jakicic JM, Ard JD, et al. 2013 AHA/ACC guideline on lifestyle management to reduce cardiovascular risk: a report of the American College of Cardiology/American Heart Association Task Force on Practice Guidelines. Circulation 2014;129:Suppl 2:S76-99. 